\title{
Is tissue glue an alternative to sutures in impacted third molar surgeries?
}

\author{
Pavan Kumar B ${ }^{1}$, Venkatesh V², Haripriya Chari ${ }^{3}$, YashwanthYadav ${ }^{4}$
}

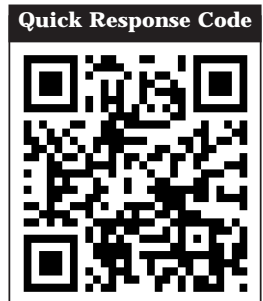

doi: $10.5866 / 2017.9 .10008$

${ }^{1}$ Professor \& HOD

2Professor

${ }^{3,4}$ Senior Lecturer

Department of Oral \& Maxillofacial Surgery,

Kamineni Institute of Dental Sciences,

Narketpally, Nalgonda, Telangana State.

\section{Article Info:}

Received: J anuary 10, 2017

Review Completed: February 9, 2017

Accepted: March 12, 2017

Available Online: March, 2017 (www.nacd.in)

(C) NAD, 2017 - All rights reserved

Email for correspondence:

pavankumarbatchu40@gmail.com

\begin{abstract}
:
Background: Achieving a good primary closurein the third molar region is critical in avoiding complications like infection, dry socket and pocket formation distal to the second molar. But this closure provides a challenge due to the low accessibility and difficulty in manipulating the tissues. As such there is a need to find easier and more reliable methods for achieving the closure.
\end{abstract}

Objective: To compare the efficacy of cyanoacrylate (tissue glue) with Vicryl sutures for closure of extraction socket following the surgical removal of impacted mandibular third molars.

Materials and Methods: Sixty patients with bilaterally impacted mandibular third molars wereselected in this study. Vicryl sutures were used for closure on one side after surgical removal ofthird molar while cyanoacrylate was utilized for closure on the other. All the patients were evaluated for bleeding, pain, and swelling, time taken for wound closure, wound healing /dehiscence, and sensitivity distal to the second molar at 1st, 2nd, 3rd, 7th \& 14th day after surgical extraction.

Results: The results showed that postoperative bleeding was not seen with cyanoacrylate. Reduced postoperative pain and swelling after the use of tissue glue was noted as compared to sutures because of less tissue handling and less tissue inflammation. The remaining data was analyzed using Paired t test, Mann-Whitney $\mathrm{U}$ test, two independent sample tests.

Conclusion: Isoamyl 2 cyanoacrylate may promote early initial healing, achieve rapid and easy closure, and may also reduce sensitivity on the distal aspect of second molar when compared with the Vicryl.

Key words: Cyanocrylate, Medicated tissue glue, Hemostasis, Vicryl, Impacted Molars

\section{INTRODUCTION:}

The objective of wound closure in any surgical procedure is to promote the primary healing. The goal of the wound closure should be to achieve precise wound approximation, decrease the risk to the patient, easy handling and working properties of the wound closure material and most important is low infection rate. ${ }^{1}$ The conventional method is to close the wound with sutures. A wide range of materials ranging from human hair to the silk sutures have been tried for a closure of wounds. I ntra 
oral suturing, especially at the third molar socket is not always easy, because of difficulty in access and the manipulation of tissue margins. Many biomaterials have been synthesized over the years as suture materials including resorbable Polyglactin. Alternateto conventional suturing, tissue adhesives such as cyanoacrylate bioadhesive have come into use, and are gaining popularity. There have not been many studies to evaluate the use of tissue adhesives in oral mucosa.

\section{Materials and Methods:}

Sixty patients with bilateral symmetrical impacted mandibular third molars (classied as per George Winter's classication)were sel ected. Patients aged 18 and 35 years of age requiring bilateral mandibular $3^{\text {rd }}$ molars surgeries with similar bone impaction and inclination on the right and left sides were included.Exclusion criteria were patients bel ow 18years of age, with uncontrolled systemic diseases (hematological diseases such as anemia, leukemia, etc.), ongoing chemotherapy or radiation therapy, immuno-compromised or immune suppressed patients, acute infective conditions around third molar, patients on anticoagulant therapy whose INR value was $>2$, smokers and patients allergic to lignocaine. All the patients were assessed for pain, bleeding, postoperative swelling, wound healing/ dehiscence, and sensitivity distal to second molar. For all the patients, documentation was completed on the $1^{\text {st }}, 2^{\text {nd }}, 3^{\text {rd }}, 7^{\text {th }}$ and $14^{\text {th }}$ day and 1 month post operatively.

\section{Examination Methods:}

1) Pain: The pain scale (Table 1) was $5 \mathrm{~cm}$ long subdivided into 5 equal parts, oneend corresponding to no pain, the other to extremely severe pain. It was recorded at immediate preoperative, 24 hours, 3 days and $7^{\text {th }}$ postoperative day. (Table I)

2) Swelling: Facial swelling (Figure 1) was determined by tape measurements ${ }^{4}$ between the tragus and soft tissue pogonion (A), tragus and lateral corner of the mouth (B), lateral corner of the eye and the angle of the mandible (C). The facial measurement was calculated as: $(A+B+C) / 3$, and facial swelling (\%) was cal culated as: [(postoperative measurement - preoperative measurement)/ preoperative measurement] $\times 100 \%$. It would be recorded at intervals that are immediate preoperative, 24 hours, $3^{\text {rd }}$ and $7^{\text {th }}$ postoperative day.

3) Hemostasis: The patients were given a scale to indicate their subjective perception of bleeding on the VAS. ${ }^{2,3,5}$ Table Il shows the reference values that were given to patients for bleeding, and the corresponding clinical situations were recorded at 24 hours, 48 hours and 72 hours. (Table II)

4) Wound Healing / Wound dehiscence: It was observed clinically at $3^{\text {rd }}, 7^{\text {th }}$ and $14^{\text {th }}$ postoperative day (Table 3).

5) Duration of the procedure: Time taken for the procedure of application of tissue glue and closure by vicryl sutures was noted from the beginning to the completion.

6) Sensitivity distal to second molar after the procedure.Sensitivity related to second molar will be evaluated by passing the probe at the CEJ and air blown at the socket in the follow up period.

Statistical Analysis:Paired t test, MannWhitney $U$ test, two independent sample tests was done using I BM (SPSS version 19)

\section{Results:}

A total of sixty patients were selected with similar bilateral mandibular third molars surgery (F igure 2 and 3). After the surgical removal, sockets were closed using cyanoacrylate glue on one side and the other side by Vicryl sutures and the heal ing was evaluated (Figure4). Among the sixty patients included in the study, 36 were female and 24 were male, with a mean age of 25.8 years. Out of sixty cases, 12 were vertically impacted, 10 were distally impacted, 16 were mesioangular and 22 were horizontal impactions.

Where Vicryl was utilized, during the immediate post-operative period, 13 patients had mild ooze after suturing and on the 1st postoperative day, 3 patients had mild ooze. The side on which tissue glue was utilized, none of the patients had any bleeding in the immediate post-operative period or on the 1st and 2nd post-operative days. 
An analysis of post-operative pain in wounds where vicryl was utilized for closure showed that, on 1st post-operative day - 25 patients had mi ld pain, 32 patients had severe pain and 3 patients had very severe pain. On 2 nd day 13 patients had mild pain, 38 patients had severe pain, and 9 patients had very severe pain. On 3rd day 9 patients had slight pain, 35 patients had mild pain, and 16 patients had severe pain. On the 7 th day 25 patients suffered from pain, in this 22 patients had slight pain and 3 patients had mild pain.

On the contrary, when glue was utilized for wound closure, on 1st post-operative day - 24 patients had slight pain, 26 patients had mild pain and 10 patients had severe pain. On 2 nd day 7 patients had no pain, 37 patients had slight pain, and 16 patients had mild pain. On 3rd day 47 patients had no pain, and 13 patients had slight pain, on the 7th day all patients wereasymptomatic.

Postoperatively mean increase in the facial swelling on 1st day was $2.58 \%$ over vicryl side and $1.55 \%$ over Glue side. Whereas on the 2 nd day i.e. $4.28 \%$ increase on vicryl side and $1.86 \%$ over glue side. On 7 th day it was $0.94 \%$ increase over vicryl side and $0.25 \%$ increase over Glue side.

On 7th post-operative day after suture removal over vicryl side, 38 sockets showed gaping and rest 22 sockets had healed adequately. On 14th day 2 sockets were non-healed, 19 sockets showed gaping and the rest 39 patients showed adequate healing.

Over Tissue glue side on 7th day after removal of the sloughed tissue glue granules 49 sockets showed gaping and 11 sockets showed adequate healing. On 14th day 8 sockets showed gaping and the rest 52 sockets healed adequately (Figure5).

Time taken for suturing and tissue glue application was noted from the beginning to the completion of the procedure on either side.M ean time taken for compl etion of suturing with Vicryl was 2.92 minutes i.e. 177 seconds whereas mean time taken for application of tissue glue was 0.34 minute i.e. 21 seconds.

Patients were asked for sensitivity by blowing air with two way syringe distal to second molar on the 7th and 14th post-operative day. Over the Vicryl side, sensitivity distal to second molar was noted in thirteen patients on 7th postoperative day and in six patients on 14th day.

Over the tissue glue side, sensitivity distal to seven was noted in two patients on 7th postoperative day whereas on 14th day.

\section{Discussion:}

Surgical removal of impacted third molars is one of the most frequently performed procedures in oral and maxillofacial surgery. ${ }^{6,7}$ The most common method of wound cl osure in oral surgery is suturing. A variety of absorbable and non-absorbable materials, ranging from animal derivatives to synthetic polymers, staples, fibrin sealants, adhesive tapes have been used from time immemorial. The sutures are time tested; conventional, standard and most commonly used means of wound closure. Sutures have their own set of drawbacks which include trauma as a result of cutting needle, lodging microorganisms, susceptibility to infection, need for removal, complications like stitch abscess, gaping of wound margins, necrosis of tissue edges and risk of needle stick injury to the operating surgeon. ${ }^{8,9}$

Polyglactin 910 (Vicryl), a synthetic absorbable suture, is prepared from a synthetic absorbable copolymer of glycolide and lactide and is totally absorbed by 40 to 60 days. These materials are absorbed via enzymatic degradation by hydrolysis or phagocytosis, resulting in less tissue inflammation. They tend to accumulate debris and cause irritation often necessitating manual removal. ${ }^{10,11}$ This has led to the introduction of easier way of wound closure by using tissue adhesives. ${ }^{12}$

Cyanoacrylates are bio adhesives (plastic adhesives) that were discovered by Ardis (a German chemist) in 1949 and rst used for surgery by Coover et al in 1959. When applied to two opposing, wet, living tissue surfaces, they havethe ability to cement them in place. Their general chemical formula is $\mathrm{CH}_{2} \mathrm{C}(\mathrm{CN})$-COOR, where $\mathrm{R}$ can be substituted for any alkyl group, ranging from methyl to decyl.

Cyanoacrylate glue is an acrylic resin, where the hardener is water. In the presence of water, 
including moisture from the air, the molecules of the glue have a chemical reaction and form into tight chains between the two surfaces being bonded. Because intraoral mucosa is naturally moist in the presence of saliva, the use of cyanoacrylate glue may nd itself as an involuntary partici pant in the bonding process. ${ }^{2,3,5}$

Polymerization of the cyanoacrylate occurs within 10-15 seconds. These are not absorbable and aresloughed from the surface of the skin and mucosa 7-10 days after adhesive application.

In this study Isoamyl 2-cyanoacrylate was compared with vicryl (polyglactin 910) suture material for wound closureafter surgical extraction of mandibular impacted third molars. During incision closure, immediate haemostasis was observed after application of cyanoacrylate tissue glue and no bleeding was observed even in the late postoperative period ( $1^{\text {st }}$ and $2^{\text {nd }}$ day). The probable explanation would be that immediately after application of tissue glue it formed a thin layer of surface coating over the incision margins and acted as a mechanical barrier for the blood flow from beneath which was strengthened by applying another thin layer over it and extending nearly $2 \mathrm{~mm}$ all over the incision site which acted as a barrier for saliva to enter. It may also have enhanced the clot formation beneath, thus enabling immediate hemostasis, highlighting the hemostatic property of cyanoacrylate. The hypothesis is that the ester forms a macrofilm, thereby forming a mechanical barrier to slow blood flow. It may also act as a surface agent to activate the clotting cascade. There is evidence that the film forms a porous mass that is invaded with blood with subsequent cl otting within the pores of the adhesive. Surindar et al (1968) studied the efcacy of cyanoacrylate in patients undergoing various minor intraoral procedures such as biopsies, extraction socket closure, gingivectomies etc, and found it to bea hemostatic adhesive that polymerizes al most immediately on contact with cut oral tissue. ${ }^{13}$

Pain was evaluated using the VAS (visual analog scale) in the present study, which was significantly higher at the suture site in comparison to the cyanoacrylate side.The irritation and local trauma from the sutures caused by the suture needle penetrating the flap (more tissue handling) and collection of food particles on the sutured area and tissue reaction to the suture material (more tissue inflammation) may be responsible for this reaction. Removal of the sutures on seventh post-operative day led to reduction in the inflammation at the sutured sites. Similar results were noted in a study by Danda et al (2010) where significant pain score was found in the primary closure group following third molar socket closure. ${ }^{14}$ In a study by Kumar et al (2013), histologically there was gap between the flaps over sutured side filled with dense inflammatory infiltrate along the margins whereas cyanoacrylate side showed no gap and uniform distribution of inflammatory infiltrate, confirming maximum inflammatory response to sutures than tissue glue. ${ }^{12}$

The post-operative pain control of cyanoacrylate can be explained by the fact that formaldehyde, one of the degradation products of cyanoacrylate, causes mild local anesthetic effect in the covered area, thereby reducing pain. Moreover, there is reduced tissue handling, less tissue inflammation and the small foramina over the acrylate side resulted in better drainage and reduced pain. These results correlate with the clinical findings reported by Giray (1997) Quinn J .V; (1993), Barnett (1998) who stated that wound closure with tissue adhesive was painless and quick.5, 15

The adhesion of the two margins of the incision by cyanoacrylate leaves no space for salivary interference during healing, thus the isolation of the wound margins from saliva and food debris/plaque appears to be an added advantage provided by cyanoacrylates al ong with its antimicrobial activity.

Overall pain and swelling was more over the suturing side when compared to tissue glue side as less amount of tissue handling and its inherent properties have added to its advantage.After surgical removal of impacted tooth, mean timetaken for completion of suturing with vicryl was 2.92 minutes i.e. 177 seconds whereas mean time taken for application of tissue glue was 0.34 minute i.e. 21 seconds. The above recordings suggest that the 
time taken for incisions closed with isoamyl 2 cyanoacrylate was remarkably less when compared to sutures. This indicates the importance of ease of application while using cyanoacrylate tissue glue in the wound closure. Similar results indicating the importance of ease of application of Histoacryl blue irrespective of the length of the incision when compared to sutures was proved in the clinical study by Kumar et al (2010). ${ }^{16}$

In the present study, the tooth sensitivity distal to second molar, was seen in significantly less number of patients, indicating the importance of cyanoacrylate tissue glue as desensitizing agent by sealing the dentinal tubules and controls the microleakage of oral fluid at the teeth's cement enamel junction of second molar. Several studies have been conducted to evaluate the bonding capacity of cyanoacrylates to dentin and enamel, including studies by Herod (1990) and Beech, 1972. ${ }^{17}$ It was found that the methyl, ethyl and isobutyl2cyanoacrylate formed strong bonds with dentin. The adhesion to dentin was probably a result of covalent bonds being formed with the organic constituents of dentin. Use of tissue glue as a potential desensitizing application was reviewed by Leggat et al (2004) thereby adding a new avenue to their usage. ${ }^{18}$

In the present study, it has been proven that cyanoacrylate adhesive has certain advantages over conventional suturing technique. It has hemostatic, desensitizing and bacteriostatic properties, is associated with reduced inflammation due to various reasons as cited above, its ease of application, and avoidance of second visit for suture removal with the added advantage of no needle prick injury definitely favor its use.

Despite these advantages, they can be used as an alternativeto sutures only in superficial incisions or lacerations. Its other limitations include the cost of the tissue adhesive, cyanoacrylate ampule crush while loading into syringe, adheres to gloves and instruments, and cannot be used in patients with known allergy to cyanoacrylates and formal dehyde.
Table I: Visual analog scale to evaluate pain: reference values given to patients. ${ }^{2,3}$
0 No Pain
The patient feels well
1 Slight Pain
2 Mild Pain
3 Severe Pain
4 Very Severe Pain
5 Extremely Severe Pain
If the patient is distracted he or she does not feel the pain
The patient feels the pain even if concentrating on some activity
The patient is very disturbed but nevertheless can continue withnormal activities
The patient is forced to abandon normal activities
The patient must abandon every type of activity

Table II: Visual analog scale to evaluate bleeding: reference values given to patients

0 No bleeding The patient does not detect any blood in saliva

1 Oozing

2 Accidental Low The patient has low bleeding Bleeding sometimes (Patient notices blood over the suturedwound which stays all over the day but does not increase in volume)

3 Continues Low The patient has low bleeding often

Bleeding (Patient notices blood with continues increase in volume)

Table III: Evaluation of postoperative wound healing ${ }^{3}$.

$\begin{array}{ll}\text { Score } & \text { Observation } \\ 1 & \text { Non Healed } \\ 2 & \text { Gaping } \\ 3 & \text { Healed adequately }\end{array}$




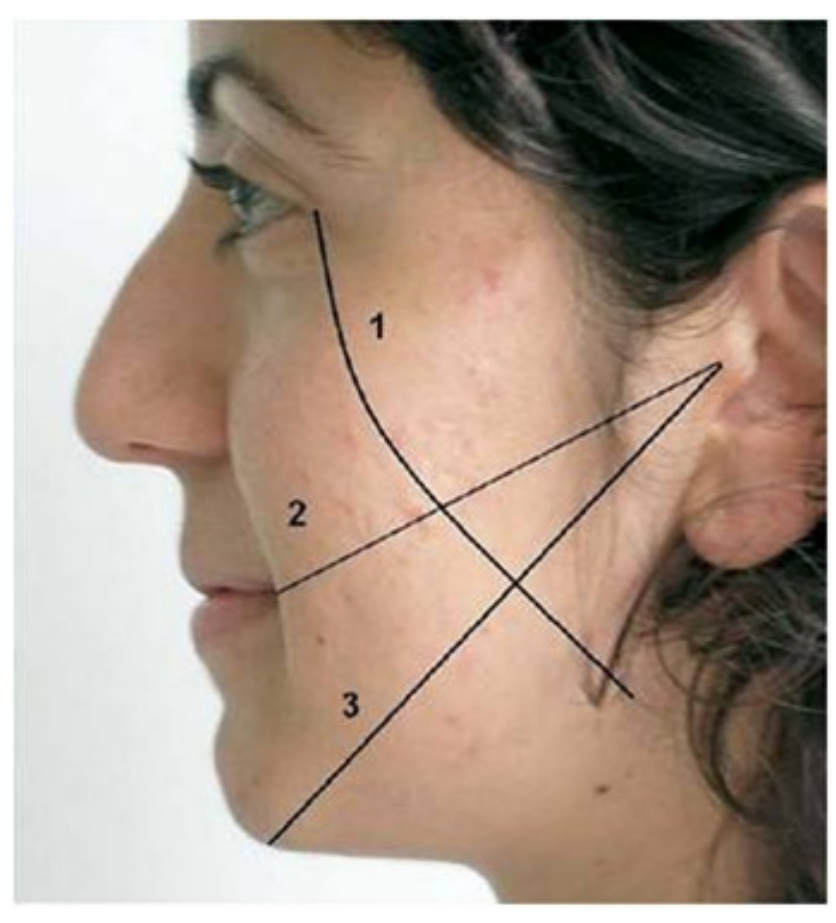

Figure 1: Evaluation of postoperative edema

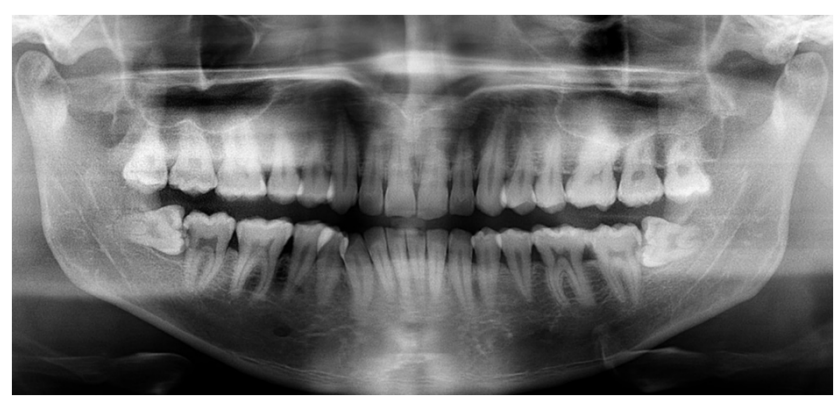

Figure 2: Pre-operative panaromic radiograph showing bilateral impacted teeth.

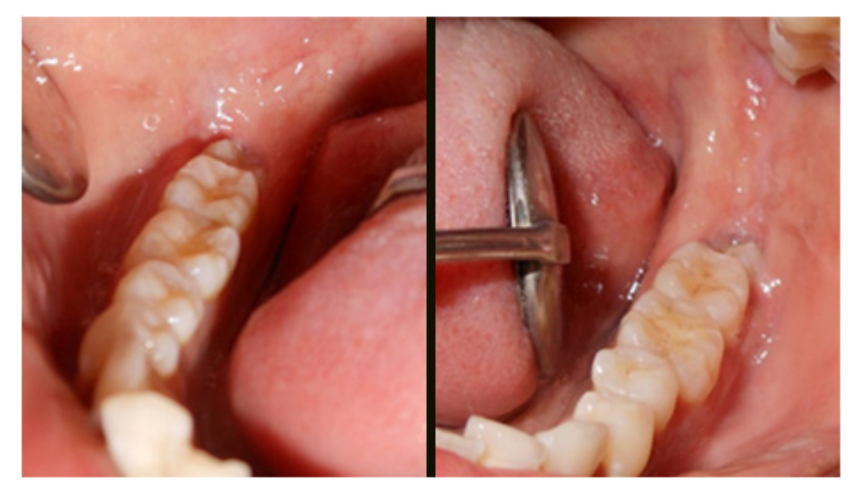

Figure 3: Pre-operative clinical picture of bilateral impacted teeth

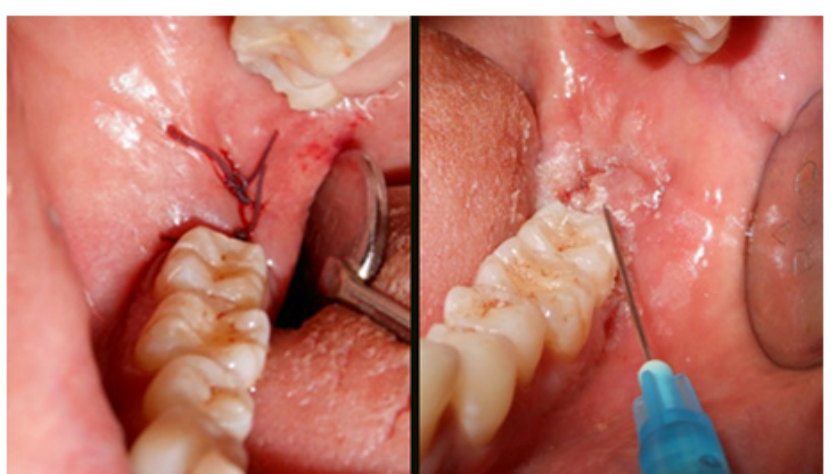

Figure 4: Intra operative clinical picture showing closure with Vicryl (left) and tissue glue (right)

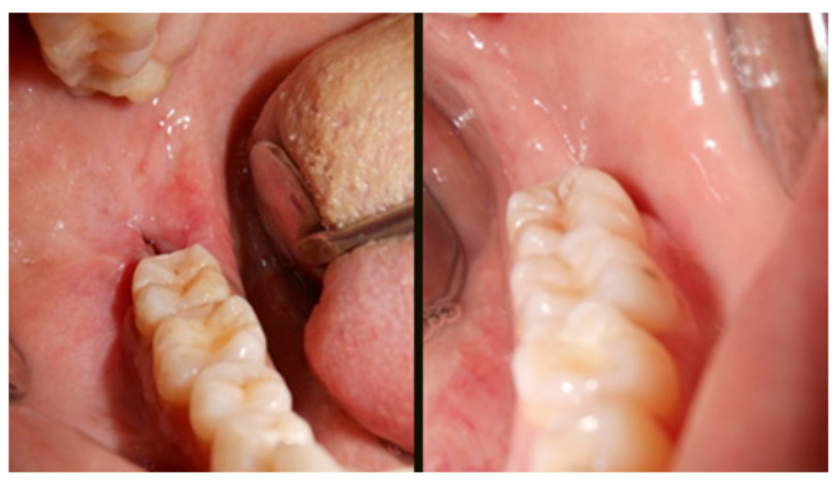

Figure 5: Healing at 14rd post operative day on Vicryl side (left) vs tissue glue side (right) 


\section{Conclusion:}

In conclusion, it can be said that the tissue glue can be used as an alternative to vicryl sutures in intra-oral mucosa especially in closure of mandibular third molar extraction sockets.

\section{References:}

1. Madan N, Kumaraswamy SV, Ashoka, Keerthi R, Ashwin DP. Evaluation of 2-Octyl Cyanoacrylate tissue adhesive as an acceptable alternative to sutures in head and neck incisions J IOH, 2010; 2(3).

2. Ghoreishian M, Gheisari R, Fayazi M Tissue adhesive and suturing for closure of the surgical wound after removal of impacted mandibular third molars: A comparative study Oral Surg Oral Med Oral Pathol Oral RadiolEndod 2009; 108(1):14-6.

3. Setiya S, Halli R, Shah A, Chhabaria G, Singh T Comparative evaluation of efcacy of tissue glue and sutures after surgical removal of impacted mandibular third molars - A prospective controlled clinical study J Oral MaxillofacSurg MedPath 2014; 7.

4. ParimalaSagar, Kavitha Prasad, R. M. Lalitha, and KrishnappaRanganath Cyanoacrylate for I ntraoral Wound Closure: A Possibility? Int J Biomaterials 2015.

5. J oshi AD, Saluja H, Mahindra U, Halli R Efcacy of tissue glue and sutures after impacted mandibular third molar removal - a comparativestudy. J Maxill ofac Oral Surg 2011; 10(4):310-5.

6. Hashemi HM, Beshkar M, Aghajani R the effect of suture less wound closure on postoperative pain and swelling after impacted mandibular third molar surgery $\mathrm{Br} J$ Oral MaxillofacSurg 2012;50(3):256-8.

7. Otasowie Daniel Osunde, Birch D. Saheeb, Rafel A. Adebola Comparative Study of Effect of Single and Multiple Suture Techniques on Inammatory Complications After Third Molar Surgery J Oral MaxillofacSurg 2011; 69:971-76.

8. Kruthi N, Rajasekhar G, Anuradha B, Krishna Prasad L. Polyglactin 910 vs. Triclosan Coated Polyglactin 910 In Oral Surgery: A Comparative In Vivo Study Dentistry.
9. Vastani A, Maria A Healing of Intraoral Wounds Closed Using Silk Sutures and Isoamyl 2-Cyanoacrylate Glue: A Comparative Clinical and Histologic Study J Oral MaxillofacSurg 2013; 71:241-48

10. Ozçaka O, Arikan F, Sönmez S, Veral A, Kendirci S. Evaluation of the Tissue Reaction of Five Different Suture Materials in Rabbit Palatal Mucosa EU DiohekFakDerg 2010; 31:29-37

11. Aderriotis D, Sandor G. Outcomes of I rradiated Polyglactin 910 Vicryl Rapid Fast-Absorbing Suture in Oral and Scalp Wounds.J Can Dent Assoc 1999; 65(6).

12. Suresh Kumar M, Natta S, Shankar G, Reddy S, Visalakshi D, Seshiah G V Comparison between Silk Sutures and Cyanoacrylate Adhesive in Human Mucosa- A Clinical and Histological Study. J International Oral Health 2013; 5(5):94-9.

13. Bhaskar SN, Cutright DE. Healing of skin wounds with butyl cyanoacrylate. J Dent Res 1969;48(2):294-7.

14. Danda AK, Krishna Tatiparthi M, Narayanan V, Siddareddi A Inuence of Primary and Secondary Closure of Surgical Wound After Impacted Mandibular Third Molar Removal on Postoperative Pain and Swelling-A Comparative and Split Mouth Study. J Oral MaxillofacSurg2010;68(2):30912

15. Giray CB, Atasever A, Durgun B, Araz K. Clinical and electron microscope comparison of silk sutures and n-butyl2-cyanoacrylate in human mucosa. Aust Dent J 1997;42(4):255-8.

16. Raj Kumar V, Rai AB, yadav $P$ Comparative evaluation of $\mathrm{n}$ - butyl cyanoacrylate and silk sutures in intra oral wound closure - A clinical study. J Adv Dent Res 2010; I(1).

17. Herod EL. Use of cyanoacrylate adhesives in dentistry. J Can Dent Assoc 1990;56(4):331-4.

18. Leggat $P$, Kedjarune $U$ And Smith DR. Toxicity of Cyanoacrylate Adhesives and Their Occupational I mpacts for Dental Staff. Industrial Health 2004; 42:207-11.

\section{Gain quick access to our journal online View our journal at www.nacd.in}

